\title{
Terrorismo etarra y televisión: TVE como agente conformador de una imagen pacífica de la transición (1976-1978)
}

\section{Eta terrorism and television: creating an image of a peaceful transition in TVE (1976-1978)}

Virginia Martín Jiménez. Universidad de Valladolid

Recibido: 21-V-2011 - Aceptado: 22-I-2013

Resumen:

Este artículo analiza el tratamiento que Televisión Española dio a las acciones terroristas de ETA durante los primeros años de la Transición democrática (1976-1978). Partiendo de la tesis de Piñuel (1986) sobre el "ritual del terrorismo", se ofrece el estudio cualitativo de la difusión u omisión televisiva de las acciones de ETA ante una selección de los hitos más significativos del cambio democratizador: Ley para la Reforma Política, elecciones generales de junio de 1977 y el proceso de redacción y aprobación de la Constitución de 1978. Las principales fuentes utilizadas han sido, junto con una actualizada bibliografía, las emisiones que custodia el archivo de TVE, los baremos de opinión del CIS y las entrevistas cara a cara y en profundidad a profesionales que trabajaron en este medio durante la Transición.

Palabras clave:

Transición democrática, Medios de comunicación, Televisión Española (TVE), Terrorismo, ETA.

Abstract:

This article analyzes how state television in Spain reported ETA terrorism during the early years of transition to democracy (1976-1978). Based on Piñuel's theory (1986) concerning the "ritual of terrorism", the author of this study shows a qualitative study about ETA actions broadcast in TV or its omission during the most relevant moments of Transition: Political Reform Law, first elections on 15th June, 1977 and adoption of the Constitution in 1978. The sources used for this study were an updated bibliography, the TVE programs from the archives of this television station, CIS surveys and in-depth and face-to-face interviews with journalists who lived through the Transition.

Key words:

Democratic Transition, Mass media, Spanish Television (TVE), Terrorism, ETA. 


\section{La incidencia del terrorismo en el cambio democrático}

Durante los últimos años del franquismo arraigó en gran parte de la sociedad española la esperanza de que la llegada de la democracia fuera acompañada de la desaparición del terrorismo. Esta ilusión, que muy pronto se desvanecería, se derivaba de una visión simplista de la violencia organizada, entendida como una respuesta al sistema dictatorial que había imperado en España desde finales de los años treinta. Si había surgido para hacer frente al totalitarismo, una vez desarticulado este, se desvanecería con él. Sin embargo, los grupos terroristas, que contaban cada uno de ellos con una dinámica propia, se convirtieron en una variable determinante del proceso de cambio (Sánchez Cuenca, 2009).

La "estrategia de la tensión" desplegada por el terrorismo durante la Transición buscaría, entre otros objetivos, dar al traste con todo el proyecto político democratizador tal y como este se estaba llevando a cabo ${ }^{1}$. Los atentados, muertes, secuestros o demás actos de violencia perseguirían la consecución exitosa del "esquema de la tenaza golpismo-terrorismo" expuesto por Muñoz Alonso (1986). Partiendo de este planteamiento, podríamos decir que cuando los terroristas entraban en acción podrían ansiar, en mayor o menor medida, que "el ruido de sables" se acrecentara, hasta el extremo de que acabara por impedir el éxito de la democratización o de la forma en la que esta se estaba desarrollando. A pesar de los objetivos diferenciales perseguidos por cada grupo, había en todos los casos un punto de convergencia: "crear una alarma tal en la sociedad que sea preciso detener la transición e imposibilitar la reforma. Se intenta provocar una involución política que, en las condiciones de la España de la segunda mitad de los setenta, no podría ser sino trágica. Terrorismo y golpismo se alimentan mutuamente de tal modo que acaban haciéndose interdependientes. La esperanza de uno radica en la fuerza del otro" (Reig Cruañes, 2000: 748).

Esta presencia constante del "terrorismo tradicional", si empleamos el término acuñado por Wilkinson (2006), fue alimentada por grupos de distinto corte ideológico y capacidad de incidencia. Entre ellos encontramos a la banda terrorista ETA (Euskadi ta Askatasuna) y a los GRAPO (Grupos de Resistencia Antifascista Primero de Octubre) como autores del mayor número de muertes durante los años que conciernen a esta investigación. Por otra parte, estarían, entre otros, las distintas agrupaciones de extrema derecha o extrema izquierda -como el FRAP (Frente Revolucionario Antifascista y Patriótico) o la Triple A (Alianza Apostólica Anticomunista) - y diversos grupos de corte independentista (Reinares, 1993).

1 Javier Casals considera que la violencia de la extrema derecha no desplegó una auténtica "estrategia de la tensión" porque "la prensa y los líderes de la ultraderecha crearon un clima de opinión favorable a un golpe de Estado, pero su violencia lo obstaculizó al neutralizar el impacto de la ejercida desde la ultraizquierda. (...) En segundo lugar, porque el terrorismo de la extrema derecha careció de táctica y estrategia (...). En tercer y último lugar, porque se impone una revisión del propio concepto de estrategia de la tensión, pues aunque este aparece claro sobre el papel, los hechos no ratifican su existencia" (Casals Meseguer, 2009: 35-36).

Sin embargo, a pesar de que el autor justifica las conclusiones a las que llega, desde nuestro punto de vista, existe una tendencia a lo largo del todo el texto a confundir una "estrategia de la tensión" fallida con la inexistencia de la misma. 
El presente trabajo se centra en las acciones perpetradas por ETA debido a su mayor virulencia, en comparación con otros grupos exaltados, durante el período que concierne a estas páginas. Durante los primeros años de la Transición (19761978) murieron víctimas de atentados terroristas 130 personas (Pulgar Gutiérrez, 2004). De todas ellas, un $70 \%$ fallecieron debido a la violencia de la banda terrorista ETA2 . De manera llamativa, a medida que avanzaba el proceso democratizador, aumentaba el número de atentados y muertes ${ }^{3}$. El incremento más notable se produjo entre 1977 y 1978, cuando se multiplicó por seis la cantidad de víctimas que este grupo violento provocó: de 17 en 1976 y 10 al año siguiente, la cifra se elevó notablemente en 1978 donde la banda contabilizó 65 víctimas mortales (Pulgar Gutiérrez, 2004).

Teniendo en cuenta estos datos y la gravedad de las consecuencias del terrorismo etarra se podría afirmar que este era una contundente amenaza para el desarrollo y la estabilidad de la Transición; hasta el extremo de llegar a convertirse, utilizando el planteamiento defendido por John Keane, en el peor enemigo de la democracia (Keane, 2004). La existencia de este adversario antidemocrático generó un frente unificador que aglutinaba a la mayor parte de las fuerzas políticas y a los medios de comunicación; puesto que para terminar con este potencial involucionista parecía necesario una estrategia de concentración nacional que agrupara a la sociedad en su conjunto, a los dirigentes del cambio y a los principales agentes socializadores, entre los cuales se encontraba la televisión (Martín Jiménez, 2011).

En este contexto, el presente trabajo, que recoge de forma parcial los resultados de la investigación que la autora de estas páginas ha desarrollado en su tesis doctoral, buscar analizar qué estrategia mediática se siguió a la hora de dar difusión a sucesos violentos protagonizados por ETA que tuvieron lugar en momentos críticos de la Transición. Los hitos del proceso democratizador se han seleccionado en función de su repercusión político-social y teniendo en cuenta lo que en dichos contextos pudiera suponer, como agente desestabilizador, la irrupción de la violencia etarra. Por ese motivo se escogieron tres momentos claves: el proceso previo al referéndum de la Ley para la Reforma Política de 1976, las semanas anteriores a las elecciones generales de 1977 y el período de elaboración y aprobación de la Constitución de 1978.

A partir de esa elección de hitos cronológicos y teniendo en cuenta los atentados terroristas que tuvieron lugar en esas fechas escogidas, se visionaron los reportajes que el programa Informe Semanal emitió tras haberse producido una nueva acción violenta de ETA. Se escogió este espacio por su relevancia dentro de la parrilla televisiva y porque, al seleccionar se-

2 Mientras que en 1977 ETA perpetró 80 atentados, un año más tarde se alcanzó la cifra de 261. Es decir, “uno cada día y medio, y un asesinato cada cinco días. El activismo etarra de finales de los sesenta y principios de los ochenta desbordó todas las previsiones y se convirtió en un eficaz instrumento desestabilizador con capacidad para poner el proceso de democratización contra las cuerdas" (Domínguez Iribarren, 2000: 350).

3 Fernando Reinares muestra una serie de posibles causas que explicarían el aumento continuo de la escalada terrorista. Entre ellas apunta las siguientes: una inadecuada gestión del cambio político, los errores y dilaciones a la hora de satisfacer las aspiraciones políticas de los nacionalismos, una política de orden público semejante a la franquista, la ausencia de una voluntad política unitaria, una respuesta policial ineficiente o diversos factores internacionales (Reinares, 1993: 611-644). 
manalmente las noticias más relevantes, con el fin de emitir un análisis profundo de ellas, su estudio puede ayudarnos a conocer qué temas destacó y/o omitió la cadena estatal (Magro, 2003)4.

Televisión Española gozaba en aquel momento del monopolio en su terreno mediático y contaba con unos crecientes niveles de audiencia. El equipamiento de televisores cubría ya el 93\% del territorio español y, según los datos del Estudio General de Medios (EGM), más del 90\% de la población declaraba que veía la televisión todos o casi todos los días (Martín Jiménez, 2011). De ahí que sea tan importante analizar qué tipo de discurso informativo acerca del terrorismo recibieron los españoles en sus hogares a través de la televisión y en qué medida ese discurso pudo influir, como se reflejó en las encuestas del CIS que se han utilizado como fuente, en su visión del cambio democrático como proceso pacífico o en su preocupación sobre la violencia terrorista. Por lo tanto, este trabajo pretende exponer cómo abordó la televisión pública la violencia de ETA y las consecuencias que este tratamiento pudo tener tanto en la consecución de la "liturgia terrorista" (Piñuel, 1986) como en la visión pacífica del cambio político que asimiló una opinión pública que mostraba una escasa preocupación ante el terrorismo en proporción al número de muertes y actos violentos que este provocó durante los primeros años de la Transición.

\section{Las posibilidades estratégicas en televisión ante el terrorismo: marco teórico y su aplicación al caso de TVE y las acciones de ETA}

Este trabajo parte del estudio del fenómeno terrorista a partir de la categoría interpretativa de "ritual" desarrollada por Piñuel (1986). Según este autor, los atentados desencadenan una dinámica social que se convierte en una liturgia en la cual van a participar tanto los agresores como la sociedad en su conjunto. La reacción social ante la violencia y la narración que de lo ocurrido hagan los medios de comunicación es lo que contribuirá a la culminación del proceso de ritualización. Como defiende el citado autor, la peculiaridad del terrorismo consiste en que es capaz de convertir una pauta social agresora en una pauta expresiva. Esto se consigue en el momento en el que los medios se hacen eco del desafío que con las agresiones se ha lanzado a la nación ${ }^{5}$. La violencia se ejecuta confiando en que tendrá un rendimiento político y social a

4 El valor de Informe Semanal como fuente se acrecienta si tenemos en cuenta que del período analizado en este artículo apenas se conservan ediciones de los Telediarios, cuyo estudio nos podría ofrecer una información muy valiosa sobre cómo se estableció la agenda informativa en la televisión de la Transición.

5 Como recuerda Sánchez Duarte: "Las acciones terroristas no son de puertas para adentro (al menos las de grupos insurgentes). Para que estas organizaciones sobrevivan necesitan figurar en las noticias fabricando eventos convulsos dotados de la espectacularidad, novedad y letalidad suficientes ( Picard, 1993, Papacharissi y Oliveira, 2008: 55) provocando, en muchas ocasiones, un sobredimensionamiento de los hechos (Torres, 2006). A raíz de los atentados del 11-S, Nacos (2002:10) acuñó la expresión de terrorismo mediatizado para referirse a la estrecha vinculación entre las actividades terroristas y los medios de comunicación. (...) De las primeras y precarias actividades de difusión anarquista pasamos a acciones más llamativas, eventos espectaculares planificados estratégicamente y diseñados desde el punto de vista del marketing" (Sánchez- Duarte, 2009:483). 
través de la codificación que de lo ocurrido puedan hacer los mass media y la posterior descodificación que lleve a cabo la opinión pública (Piñuel, 1986).

La consecución del "ritual terrorista" se alcanza cuando los exaltados logran la resonancia mediática buscada. El tipo y cuantía de la difusión de la violencia, en otras palabras el "rendimiento comunicativo" del que habla Piñuel, es determinante a la hora de que el terror consiga los objetivos buscados. El propósito fundamental es difundir, a través del eco que puedan tener sus actuaciones, un mensaje muy concreto que aspira a modificar la opinión pública y posicionarla a favor de la postura que más favorezca a los fines terroristas (Piñuel, 1986: 10-11).

Esa resonancia mediática de la violencia pudiera incluso llegar a proyectar una imagen tal del terrorismo que acabe por otorgar a cada grupo violento esa "máscara de omnipotencia" de la que nos habla Pearlstien (1991). Esta metáfora pretende, de manera muy expresiva, hacer reflexionar sobre la posible capacidad de los medios de conceder un protagonismo a los terroristas que no se corresponde con su capacidad real, tal y como también han defendido Jenkins (1984) y Wilkinson (1990). Así pues, según estos autores, la violencia organizada se aprovecha del impulso difusor que les pueden proporcionar los medios, hasta el punto de que para ciertos autores, como Acquavive, el terrorismo se sirve de los mass media para hacer proselitismo y captar adeptos.

Por tanto, los terroristas con sus acciones ponen en marcha un hecho noticioso que aspira a encontrar un significativo eco mediático; sin embargo, la elaboración de la noticia y su repercusión queda completamente al margen de estos actores violentos. Son los medios los que, a través de lo que transmiten, pueden reforzar el terrorismo o bien promover que la sociedad rechace este tipo de actuaciones. Dicho con otras palabras, son los medios de comunicación los que tienen en sus manos posibilitar o impedir que se pueda concluir la "liturgia terrorista". La canalización mediática de los atentados, sin que estemos delegando en ella toda la responsabilidad ante la posible o no persistencia del terrorismo, tendría en gran medida la capacidad de deteriorar esa "máscara de omnipotencia" a partir del tratamiento que diera a lo acontecido, impulsando así el rechazo social ante dichos actos o generando indiferencia hacia ellos. Este efecto de repulsa o apatía se podría conseguir más eficazmente cuanto mayor sea el índice de impacto del medio en la población. En el caso del período que concierne a estas páginas, la televisión llegaba, como hemos indicado anteriormente, a un espectro muy elevado y heterogéneo de la opinión pública y, gracias al enfoque de los contenidos de su programación, tenía la capacidad de traer a los hogares españoles “la sangre al cuarto de estar", como expone Clutterbuck, logrando que la audiencia sintiera más cercanas a las víctimas y rechazara con más virulencia el modo de operar de los terroristas (Clutterbuck, 1985: 165-166).

Otra alternativa posible para intentar detener la consumación del "ritual terrorista" sería la del "apagón informativo"; es decir, silenciar las informaciones relativas a estos episodios violentos de tal manera que sus autores no lograsen cumplir sus objetivos y acabaran así por desistir en sus actuaciones. No obstante, este silencio puede provocar que la sociedad termine por resignarse ante este problema por considerarlo "algo cotidiano e inevitable" (Clutterbuck, 1985: 586). 
A lo largo del período que abarca la presente investigación, podría decirse que la cadena televisiva estatal optó por una vía intermedia en la que se combinaron ambas estrategias de ruptura del "ritual": informar sobre lo ocurrido pero sin proyectar esa "máscara de omnipotencia" de ETA y, en otras ocasiones, apostar por el “apagón informativo". Ambas medidas, buscarían, como han declarado quienes dirigieron y trabajaron durante la Transición en TVE (Martín Jiménez, 2011), posibilitar la continuación de un proyecto muy concreto de continuismo-reformista político de carácter pacífico y sin que el terrorismo supusiera un obstáculo insuperable. Como afirma el periodista Eduardo Sotillos, que formaba parte de la plantilla de Televisión Española durante la etapa analizada en este trabajo, "se intentó actuar con prudencia; puesto que hubo momentos, que por su gravedad, llevaban a establecer un compromiso entre todos los profesionales de la información con el fin de no poner en riesgo la democracia. No se podía transmitir la sensación de un país que se desmoronaba. Tengo que reconocer que se medían mucho los contenidos debido a esa prudencia y a esa complicidad con la que se trabajaba. Y tanto los periodistas como todas las fuerzas políticas así lo entendieron" (Entrevista personal, marzo 2011).

Por lo tanto, como veremos a continuación, para impedir la consecución exitosa de esa liturgia, TVE hizo un uso particular del llamado por Miquel Rodrigo "tratamiento selectivo"; el cual parte de la necesidad de informar de los actos terroristas pero de modo diferente a como se hace con otro tipo de noticias: "se pretende convencer al público de que la causa terrorista no es buena ni conveniente" (Rodrigo, 1991: 62). Sin embargo, mientras que este autor rechaza el silencio informativo como estrategia, la cadena estatal jugó con combinar "el apagón informativo" con la difusión de los hechos según ciertos criterios de establecimiento de la agenda impuestos ante las circunstancias políticas que rodearon cada acción violenta. Esta estrategia televisiva estaría vinculada en gran medida a la estrategia gubernamental puesto que en aquellos años la cadena pública aún no contaba con un marco legal que la posibilitara trabajar con mayor independencia con respecto al partido gobernante ${ }^{6}$.

La difusión u omisión que TVE pudo hacer de aquella violencia terrorista y la manera en la que codificó dicha información para transmitirla a la sociedad como si se tratara de hechos aislados, sin demasiada repercusión y que no tenían suficiente capacidad de desestabilizar el sistema político e imposibilitar el cambio democratizador, influiría en la opinión pública a la vez que podría propiciar la conformación de un imaginario colectivo de la Transición democrática que ha perdurado en el tiempo como un proceso elogiado por su carácter pacífico. Con lo cual, la selección diaria que los profesionales de televisión realizaron de los acontecimientos violentos que fueron jalonando esta época de cambio y la consecuente tematización del interés general que esta agenda mediática provocó, terminarían por imprimir unos sesgos persistentes en la representación social del imago del terrorismo como una realidad que terminaría por desparecer y que carecía de la capacidad real de modificar el discurrir de la Transición.

6 Hay que tener en cuenta que durante gran parte del período que concierne a este trabajo, el director de RTVE era Rafael Ansón Oliart (julio 1976-noviembre 1977), hombre de confianza del presidente del Gobierno Adolfo Suárez. Su nombramiento al frente de este medio estatal fue el primero que Suárez hizo cuando llegó a la presidencia en 1976. 
Así pues, la percepción que los televidentes tendrían de la realidad terrorista estaría en gran medida supeditada a la representación simbólica que de ella se haría a través de la pequeña pantalla; de la misma manera que la razón que el público pudo atribuir a la existencia de la violencia terrorista habría sido canalizada a través de este medio al influir en la opinión pública mediante la articulación de la agenda informativa.

Como hemos comentado anteriormente, tanto por el hecho de tratarse de una televisión pública aún no regulada por un estatuto como por el hecho de que ni siquiera contara con un marco legal constitucional, la agenda mediática televisiva se desarrolló tan en armonía con los intereses de los dirigentes de la Transición, que podría llegar a afirmarse que durante estos primeros años de la Transición el poder estatal se convirtió en Gatekeepery, al representar ese papel de orientador y seleccionador de noticias, hizo coincidir la agenda televisiva con la agenda institucional (Martín Jiménez, 2011). Es decir, TVE jugó durante la Transición con el influjo social que le brindaba la jerarquización de las noticias a través de la agenda que marcaba los contenidos de la parrilla televisiva. Al seleccionar, silenciando unos temas u otorgando protagonismo a otros, lograba canalizar la atención del público y crear un ambiente favorable a la consecución de un cambio democrático pacífico a partir de un proyecto dirigido y liderado, principalmente, por el Rey y por el presidente del Gobierno. Un proyecto cuya implantación y consecución exitosa sólo podría darse si la sociedad reaccionaba de forma pacífica ante los actos de violencia. Con lo cual, si se difundía un clima de enfrentamiento y tensión a través de medios con tanta repercusión como la televisión, podía ponerse en peligro el proyecto de Transición.

Por lo tanto, en programas informativos como Informe Semanal la atención de los usuarios televisivos fue canalizada de tal forma que los aspectos positivos de la evolución democrática (ampliación de libertades, amnistía, legalización de los partidos, participación ciudadana en las urnas, etc) impregnaron más que los actos negativos como la virulenta y la constante acción de ETA. Todo esto se llevó a cabo rozando los límites del aún no promulgado, derecho a la información, pero sin llegar a caer en la censura (Martín Jiménez, 2011). Por ello, a la hora de dar cobertura informativa a los actos terroristas en los reportajes del semanario que puso en marcha Pedro Erquicia en 1973, tan sólo se analizaron, y sin demasiada profundidad, aquellos episodios que por su virulencia resultaba imposible acallar ante la sociedad, aprovechando además esos minutos televisivos para enviar a la opinión pública un mensaje que favoreciera la continuación de la labor democratizadora pacífica a pesar de las consecuencias de la violencia etarra.

\section{La imagen de la violencia etarra en la pequeña pantalla: el intento por desmantelar la "máscara de omnipotencia"}

Para hacer frente a "la estrategia de la tensión" desplegada por el terrorismo etarra, e impedir la consecución del "la liturgia de la violencia", Televisión Española, como ya se ha apuntado en estas páginas, se valió de un matizado "tratamiento selectivo" que combinaba información con omisión a la hora de enfrentarse a un nuevo episodio protagonizado por ETA.

doxa.comunicación | nº 16, pp. 63-84 | 69 
No obstante los atentados, secuestros o brotes de violencia que tuvieron más resonancia -por sus consecuencias o por sus víctimas- disfrutaron de espacio en reportajes monográficos como los que se analizan a continuación. En este apartado abordaremos un análisis minucioso de una selección de reportajes elaborados para Informe Semanal en los que se trataron de forma independiente hechos violentos relacionados con ETA que tuvieron lugar en momentos clave de la Transición: las semanas previas a la aprobación de la Ley para la Reforma Política, el camino hacia las elecciones generales de junio de 1977 y el proceso de redacción y aprobación de la Constitución de 1978.

Mediante el análisis cualitativo del discurso desarrollado en los reportajes seleccionados podremos tratar de conocer qué tratamiento dio TVE a las acciones etarras que, según los criterios selectivos de la cadena estatal, merecieron por su relevancia un reportaje monográfico en el espacio de Informe Semanal. Analizaremos, por tanto, la crónica televisiva del asesinato del presidente de la Diputación Provincial de Guipúzcoa, el secuestro de Javier Ybarra y los disturbios acaecidos durante los Sanfermines de 1978.

\subsection{ETA mata a Araluce}

Pocas semanas después de que Adolfo Suárez hiciera público el proyecto de Ley para la Reforma Política, la banda terrorista ETA volvió a matar tras varios meses de inactividad. La fecha escogida fue el 4 de octubre de 1976 y las víctimas, el presidente de la Diputación Provincial de Guipúzcoa y Consejero del Reino, Juan María Araluce, su chófer, José María Elicegui Díez, y sus tres escoltas, Alfredo García González, Antonio Palomo Pérez y Luis Francisco Sanz Flores. Se trataba del primer atentado de envergadura política que se producía tras la llegada de Suárez a la presidencia.

Trascurridos cinco días de este atentado, Informe Semanal dedicó uno de sus reportajes a lo ocurrido ${ }^{7}$. El programa arrancó con la imagen, prolongada durante varios minutos, de un reloj de pared en el despacho del presidente de la Diputación. De fondo, la voz en off comenzaba a relatar lo sucedido con un tono más apropiado de un thriller que de un guión informativo sobre un atentado: "Estas dos campanadas son las últimas que escuchó el señor Araluce en el interior de su despacho de la Diputación de Guipúzcoa. Quince minutos más tarde abandonaría su despacho para dirigirse a su domicilio a almorzar. Abajo le esperaba su escolta. (...) Cinco minutos después, estas cinco personas estaban muertas”".

Tras estas palabras se reproducía el sonido magnetofónico de la que fue la última entrevista de Araluce, para dar paso a unos minutos un tanto macabros en los que, mediante planos subjetivos y el sonido de los latidos de un corazón, la cámara iba recorriendo el mismo camino que hizo la víctima antes de iniciar, "su último viaje". La imagen de una calle con ramos de flores en la acera y una bandera de España con un lazo negro conducía al espectador hasta el lugar del atentado,

\footnotetext{
Centro de Documentación de TVE, Informe Semanal. ETA mata a Araluce, emitido el 9 de octubre de 1976.

8 Ibídem.
} 
donde habían llegado, siguiendo el mismo método del plano subjetivo, dos automóviles en los que viajaban el presidente de la Diputación y su escolta: “Apenas doscientos metros separaban de la muerte a la comitiva (...). Al llegar a la altura de la (...) residencia del señor Araluce, uno o varios individuos desconocidos, más tarde autoidentificados como miembros de la organización terrorista ETA, irrumpieron en la escena sembrando de forma implacable la muerte". La imagen se detenía y se escuchaba una sonora ráfaga de disparos, tras la cual se hacía el silencio mientras se volvían a enfocar las flores y la bandera.

A lo largo del reportaje fueron pocas las ocasiones en las que desapareció una marcada tendencia al amarillismo. Un guión sensacionalista reconstruía al espectador, con todo detalle, cómo se había producido el asesinato de Araluce; pero tan sólo una vez se llegó a nombrar a los autores de dichas muertes. No se hizo ningún tipo de análisis en profundidad de lo ocurrido, de la reacción del Gobierno o de la sociedad ante los hechos y el único mensaje que se trasmitió, y se hizo en boca de la familia del presidente de la Diputación, fue el de mirar hacia el futuro, mantener la serenidad y perdonar9. Así, el reportaje terminaba con esa imagen de la bandera de España con un lazo negro mientras se escuchaba lo siguiente: "Pero lo que no podemos dejar de destacar en toda una serie de luctuosos sucesos que han llevado una vez más la muerte a numerosos hogares españoles es el sereno reflexionar de las víctimas que han quedado con vida: los hijos, los padres, las esposas; al mirar hacia atrás sin ira".

\subsection{Secuestro en Neguri}

En el mes de mayo de 1977, cuando España se preparaba para las primeras elecciones generales de la Transición, Informe Semanal dedicó uno de sus reportajes al secuestro del industrial vasco Javier Ybarra. El programa se emitió una semana después de producirse la acción terrorista, cuando el rehén aún se encontraba en paradero desconocido, y a pesar de que se avisaba al espectador de que se trataba de un trabajo que no había sido contrastado y tratado con la diversidad de fuentes que hubieran sido necesarias, no deja de resultar llamativo la ligereza con la que el guión de Ramón Colom transmitió lo ocurrido ${ }^{10}$.

9 Dentro de las declaraciones que hicieron la mujer y los hijos de Araluce se puede escuchar lo siguiente: "Estamos muy contentos de que le tenemos a Juanmari en el cielo y nos está ayudando desde allá (...). Les perdono a todos los que le han matado y queremos que se termine el odio. Estamos rezando mucho por todos ellos. Y les perdonamos de todo corazón”: Centro de Documentación de TVE, Informe Semanal. ETA mata a Araluce, emitido el 9 de octubre de 1976.

10 Centro de Documentación de TVE, Informe Semanal. Secuestro en Neguri, emitido el 28 de mayo de 1977: "Informe Semanal hubiese querido ofrecerles la versión completa y contrastada de todo lo sucedido en torno a este suceso. Ello no ha sido del todo posible. La familia del secuestrado se ha cerrado en un mutismo total, no facilitando ninguna información. Otros personajes no han querido hablar delante de nuestras cámaras por temor a posibles represalias de ETA”. 
El reportaje comenzaba con un somero repaso, a través de imágenes, de lo sucedido las semanas anteriores al secuestro en el País Vasco: huelgas, constantes disturbios con motivo de la jornada pro-amnistía, diversos enfrentamientos con las fuerzas de orden público, etc. Tras breves planos de gente corriendo por la calle, ikurriñas en los balcones de los hogares, diferentes disturbios o actos vandálicos; la voz en off recordaba lo sucedido y apuntaba que con el asesinato de un miembro de la policía en San Sebastián, ETA había vuelto a tomar las armas casi diez días antes de lo que habían anunciado los portavoces de la banda. Sin embargo, como solía ser habitual cuando se informaba en Televisión Española sobre terrorismo, y a pesar del poco tiempo que había trascurrido entre lo que se narra y la emisión del programa, el guionista presentaba todos esos sucesos violentos como hechos pasados y ya completamente superados cuando el día 20 de mayo se produjo el secuestro.

Tras explicar cómo la tensión había disminuido notoriamente en el País Vasco, en comparación con los días anteriores, Colom iba narrando, como si de una crónica negra se tratara, los pasos que recorrió ETA para secuestrar al empresario. A través de un travelling, la cámara conducía al espectador por las calles de Neguri hasta llegar a la residencia "Los Nardos" donde vivía Ybarra. Se reproducía el procedimiento que se llevó a cabo en el secuestro, la huida de los terroristas, la reacción de la familia y cómo, a través de un comunicado etarra, se supo quienes tenían retenido al empresario.

El reportaje llegaba a su fin sin hacer un análisis de las repercusiones de lo sucedido y sin profundizar en el problema del terrorismo ni en sus consecuencias. Tan sólo en el colofón del guión encontramos un intento de ahondar en lo ocurrido. El mensaje final que recibieron los espectadores llevaba una serie de ideas implícitas: había un frente unido en la sociedad vasca en contra de la actuación terrorista; pero al no quedar expuesto si esa misma oposición existía en el resto de España, daba la sensación de que se consideraba que era una cuestión que implicaba únicamente al País Vasco; por otra parte, según el guionista, la violencia no era un continuum en el proceso democrático, sino una oleada que ya había pasado y cuyo regreso había que evitar, más aún teniendo en cuenta la cercana cita con las urnas, con lo cual se admitiría, aunque de forma bastante tímida, la proyección nacional de lo que se denominaba "problema vasco"11.

El trágico desenlace de este secuestro no quedó reflejado en Informe Semanal por medio de un reportaje monográfico, aunque sí ocupó unos minutos dentro del programa especial sobre Suárez que este informativo emitió a comienzos de julio de $1977^{12}$. Tras trazar una vaga cronología de la actividad de Suárez en el Gobierno, la voz en off recordó hechos como los secuestros de Oriol y Villaescusa o la matanza de los abogados de Atocha. En este recorrido general se hacía referencia a Ybarra, cuyo asesinato había sido perpetrado pocas semanas antes de la emisión de este programa. Para narrar lo suce-

11 "En el País Vasco todos quieren la liberación de Ybarra; ello contribuiría a un decrecimiento de la tensión de cara a las próximas elecciones del 15 de junio. A la vez se evitaría el retorno a la violencia como la oleada que se ha vivido en semanas anteriores": Centro de Documentación de TVE, Informe Semanal. Secuestro en Neguri, emitido el 28 de mayo de 1977.

12 Centro de Documentación de TVE, Informe Semanal. Gobierno de Suárez, emitido el 2 de julio de 1977. 
dido, el guionista hizo uso de un recurso muy habitual en la producción de Televisión Española durante la Transición: superponer planos de titulares de periódicos en un intento por desarrollar un reportaje objetivo que describiera los hechos sin que los periodistas tuvieran que implicarse o hacer suyos determinados juicios de valor.

\subsection{Crítica situación en el País Vasco}

A los actos de violencia callejera o a los numerosos sucesos violentos que ocurrieron en el País Vasco y Navarra a lo largo de la Transición, apenas se les prestó atención en los reportajes de Informe Semanal, puesto que se quería transmitir una imagen de orden y tranquilidad. Una de las excepciones a esta pauta de actuación la constituye el programa que se emitió con motivo de los acontecimientos ocurridos durante la celebración de San Fermín en $1978^{13}$.

Crítica situación en el País Vasco se difundió unos días después de que se suspendiera la popular fiesta pamplonica ${ }^{14}$. La mayor parte del reportaje consistió en un fotomontaje, a través del cual se intentaron reproducir los hechos. A pesar de la gravedad de lo sucedido no se trazó ningún tipo de vinculación entre lo ocurrido y la "problemática vasca", término habitualmente por Televisión Española para hacer referencia al terrorismo etarra y a la cara más violenta del nacionalismo vasco.

De modo somero y bastante confuso se informaba de la muerte de un joven con motivo de un enfrentamiento con la policía, del atentado que mató a un juez de paz en Lemona y de las protestas callejeras que se produjeron, como reacción ante estos hechos, en Bilbao. Sin embargo, se transmitió de forma ambigua la relación entre lo sucedido en Pamplona y lo ocurrido en el País Vasco, a pesar de que el título del reportaje sobre los Sanfermines no hacía referencia alguna, al menos de manera directa, a Navarra; al igual que tampoco se dijo con la claridad necesaria quienes fueron los autores de dichas muertes.

La actuación desmedida de las fuerzas de orden público, que tanto recordó al comportamiento de la policía franquista, fue uno de los puntos más tratados a lo largo del reportaje; a la vez que se recordaba cuál había sido la reacción del ministro del Interior, Martín Villa y cómo el Gobierno había “informado ampliamente” de lo sucedido (Tusell, 1999: 95). La voz en off, tras presentar un comunicado del Partido Nacionalista Vasco en el que éste se lamentaba de que "el interés general por el problema vasco sólo se suscite por hechos trágicos", explicaba que el PNV ofrecía "su apoyo para encontrar solución a los problemas de Euskadi y España".

13 De una manera un tanto discreta se hizo referencia en otros reportajes a la responsabilidad etarra en actos violentos ocurridos en el País Vasco. Así ocurrió con el programa que Informe Semanal emitió, en 1978, al día siguiente de que una bomba hiciera explosión en la central nuclear de Lemóniz, en Vizcaya: "Los grupos radicales vascos aprovecharon los planteamientos de los ecologistas sobre el impacto medioambiental de Lemóniz para orquestar una campaña que fue apoyada por los terroristas de ETA” (Magro, 2003: 52).

14 Centro de Documentación de TVE, Informe Semanal, Crítica situación en el País Vasco, emitido el 15 de julio de 1978. 
La última parte del programa se centraba en la repercusión que estos hechos habían tenido en la prensa y la postura que los rotativos habían tomado ante lo sucedido. Al final, el guión resaltaba cómo los principales periódicos del país, haciendo balance de lo ocurrido, consideraban que lo fundamental eran los acuerdos que pudieran gestarse entre el partido vasco y el Gobierno. "La expectativa tiene un nombre”, fue la frase que sirvió para terminar el reportaje, aunque al espectador se le dejaba con la duda de a qué se había referido exactamente el guionista con dicha afirmación.

\section{4. "Apagón informativo": Cuando el terrorismo no es noticia}

Entre 1976 y 1978, ETA causó la muerte de casi un centenar de personas. En enero de 1976, la explosión de una bomba acabó con la vida del guardia civil Manuel Vergara Jiménez en la localidad de Villafranca de Oria (Navarra); fue el primer atentado de la banda en la Transición democrática ${ }^{15}$. Tras éste se sucedieron muchos más que dejaron un largo listado de víctimas (Pulgar Gutierrez, 2004). El año 1978 fue especialmente cruento en comparación con los anteriores. El objetivo de los terroristas parecía haberse centrado en tratar de desestabilizar el proceso constitucional y de ahí que multiplicaran las acciones violentas en el mes anterior al referéndum; durante el cual, "en apenas treinta días, ETA realiza treinta y dos acciones terroristas que dejan un saldo de quince personas asesinadas. El balance de un atentado diario y un asesinato cada dos días da una idea cabal de la intensidad del esfuerzo terrorista empleado contra la Constitución" (Elorza, 2000: 294).

A pesar de la repetida incidencia de la actividad terrorista durante los meses en que se redactó el texto constitucional y la influencia que esta ejercició en el proceso de elaboración de la Carta Magna y su aprobación en referéndum, la televisión tendió a minimizar esa violencia y trató de que el espectador no relacionara los actos de terrorismo con la oposición de los exaltados a la Constitución. La cadena estatal hizo un importante esfuerzo por incluir en la parrilla televisiva a la Carta Magna, y a todo lo relacionado con ella, en un gran número de programas especiales, coloquios, emisiones de los debates constitucionales en el Congreso y en el Senado, reportajes elaborados para Informe Semanal (casi una docena), o espacios divulgativos sobre su contenido. Esta programación, destinada a informar a la sociedad con profundidad sobre la elaboración, el contenido y las circunstancias que rodearon al nacimiento de la Carta Magna, no prestó atención a la grave situación por la que atravesaba el país y su Gobierno debido al recrudecimiento del terrorismo etarra. Habrá que esperar a la aprobación del texto en el referéndum del 6 de diciembre de 1978, para que ese mismo día en el debate, presentado por José Antonio Silva, Tribuna de Historia, titulado La Constitución de 1978, se expusiera, antes de que arrancara el coloquio, un pequeño reportaje en el que se resumían las principales etapas que se habían sucedido durante el proceso de elaboración. A lo largo de la narración, la voz en off hizo referencia a las dificultades que, a este delicado proceso, había añadido la constante actuación del terrorismo. Sin embargo, tras este breve comentario no volvió a tratarse el

15 Cuatro días después de la muerte de Franco, ETA asesinó a Antonio Echeverría, alcalde de Oyarzún. Sin embargo, habiendo pasado tan poco tiempo desde el fallecimiento del dictador no consideramos que se pueda ya hablar de Transición. 
tema ni siquiera a lo largo del debate posterior en el que participaron Luis Sánchez Agesta, Jose Luis Sampedro, Justino de Azcárate y Sebastián Martín Retortillo ${ }^{16}$.

En relación con los distintos debates que se emitieron en la pequeña pantalla, cuyo número se amplió a lo largo de la Transición, resulta significativo el silencio en torno al problema terrorista. Entre todos ellos destacaron espacios como $\mathrm{La}$ Clave, de José Luis Balbín; Cara a Cara, coloquio moderado por Federico Ysart; o España hoy con José Javoloyes y Fernando Ónega. En ellos se trataron temas tan variados y relevantes como la reforma política, la Constitución, la crisis económica, la cuestión de las autonomías o la libertad de enseñanza. Sin embargo, la lacra del terrorismo no se llegó a tratar como el tema central a debatir durante los primeros años de la Transición.

A lo largo del periodo en el que se centra este trabajo, la mayor parte de los atentados de la banda terrorista ETA estuvieron dirigidos, principalmente, contra las fuerzas militares o policiales. También fueron objetivo de los etarras, empresarios, concejales o alcaldes de diversas localidades vascas. Sin embargo, TVE sólo dio una amplia difusión de los actos terroristas cuando las víctimas eran destacados empresarios o altos cargos políticos. Basta con echar un vistazo a los reportajes especiales dedicados a la labor de Suárez en el gobierno para comprobar cómo sólo se prestó atención a esa información, aunque sin ahondar demasiado, cuando se trató de casos como el asesinato del presidente de la Diputación de Guipúzcoa, Juan María Araluce, en 1976 o el de la Diputación de Vizcaya, Augusto Unceta, al año siguiente ${ }^{17}$.

La producción audiovisual que elaboró TVE sobre Adolfo Suárez y su labor política fueron especialmente abundantes durante los primeros años de su gobierno. Programas especiales, que se insertaron en la parrilla televisiva con motivo de alguna conmemoración destacada, o numerosos reportajes de Informe Semanal trazaron, en líneas generales, un resumen de los principales acontecimientos ocurridos durante un periodo concreto. Estas producciones tendieron a exaltar la figura del Presidente, realzando todo aquello que podía favorecer al Ejecutivo, mientras se encubría o suavizaba lo que podía resultar perjudicial para el proyecto de Transición o sus dirigentes. Un ejemplo muy significativo de esta actitud fue el documental elaborado a raíz de la conmemoración del primer aniversario de las elecciones generales del 15 de junio de 1977. Durante más de una hora, unas imágenes y un guión muy cuidados recordaban a los espectadores los hitos más destacados que habían marcado la evolución del país. Sin embargo, en ningún momento se hizo referencia a la insistente presencia del terrorismo en esos doce meses, a lo largo de los cuales ETA terminó con la vida de más de veinte personas ${ }^{18}$.

16 Centro de Documentación P.P. II TVE, Tribuna de la Historia: La Constitución de 1978, emitido el 6 de diciembre de 1978.

17 En relación a la atención que dedicó la prensa a las víctimas del terrorismo de ETA, Sánchez Duarte y Sampedro han estudiado su presencia o ausencia en las agendas de dos periódicos de referencia en España. En lo que respecta a El País, los autores destacan que el tratamiento que este diario dio a dichas víctimas en los primeros años de la Transición se caracterizó por "un desinterés absoluto. Ninguno de los años comprendidos en esa etapa superó las 10 piezas” (Sánchez-Duarte y Sampedro, 2011: 190).

18 Centro de Documentación de TVE, Especial 15 de junio. Un año de democracia, emitido el 15 de junio de 1978. 
Fueron muy escasos los ejemplos de reportajes sobre el gobierno de Suárez en los que existía un espacio dedicado al problema del terrorismo etarra. Cuando éste aparecía, normalmente ante el asesinato de determinadas personalidades políticas, solía hacerlo con un esquema muy concreto del que puede servir como ejemplo el relato que se hizo del atentado contra José María Araluce en el Informe Semanal titulado 100 días de Suárez. Después de que la voz en off hiciera referencia, de forma concisa y objetiva, a la muerte del presidente de la Diputación de Guipúzcoa, aparecía en la pantalla el ministro del Interior, Rodolfo Martín Villa, condenando el acto terrorista y recordando que el Gobierno iba a continuar con el proceso democrático. Este mensaje de no claudicación quedaba reforzado al enlazar la imagen de la violencia terrorista con otra en la que se reflejaba el buen discurrir del cambio en España. En este caso el acontecimiento positivo que se escogió fue la inauguración, por parte de los Reyes, del curso académico de la Universidad de Salamanca mientras se escuchaba lo siguiente: "la convivencia y paz de todos los españoles es el leitmotiv del Gobierno. Una paz que empieza a labrarse desde las mismas aulas de la Universidad" .

Un esquema semejante se reproduce en el reportaje Cien días para la democracia, en el cual se narra, durante unos pocos minutos, el asesinato del presidente de la Diputación de Vizcaya, Augusto Unceta ${ }^{20}$. Aunque dicho suceso ocurrió apenas una semana antes de la emisión de este documental, el mensaje que se transmitió parecía indicar que el terrorismo era un problema casi superado por el país y así, tras enlazar el atentado de ETA con otros, como el perpetrado contra El Papus, la voz en off recordaba cómo el Gobierno, tras haber detenido a varios terroristas implicados en los sucesos, continuó trabajando por la democratización de España: "la violencia del terrorismo, condenado por todas las fuerzas políticas del país, no han interrumpido los contactos dirigidos a cerrar el capítulo de la amnistía. Las maniobras desestabilizadoras volvieron a fracasar"21.

Televisión Española intentaba difundir en su programación un clima de normalidad que tranquilizara a la población y la concienciara de que el cambio democrático era posible, puesto que España contaba con un gobierno sólido y estable que apostaba por una actitud pacífica de diálogo. Este mismo mensaje era el que el Ejecutivo trataba de lanzar a los ciudadanos, sobre todo ante momentos difíciles que pusieron en peligro el proceso. Así, las palabras que Adolfo Suárez transmitió ante las cámaras, tras los graves acontecimientos de la llamada Semana negra de 1977, encerraban ese mismo espíritu promovido desde la dirección de TVE: “Deseo, sin embargo, que quede una cosa muy clara: (...) de preocuparnos ante los

19 Centro de Documentación de TVE, Informe Semanal. 100 Días de Suárez, emitido el 16 de octubre de 1976.

20 En este caso se repetía la misma estructura en el guión: se recordaba el atentado, aparecía el mensaje de Martín Villa y, finalmente, la voz en off resaltaba la fortaleza del Gobierno y la intención de continuar el camino hacia la democracia. En este caso las palabras del ministro del Interior eran claramente representativas de la actitud que el Gobierno quería transmitir a la opinión pública: “sólo desde la serenidad y desde la firmeza se puede asegurar la culminación de ese proceso y sentar las bases de un futuro de paz y libertad para todos los españoles". Centro de Documentación de TVE, Informe Semanal.100 Días del gobierno de Suárez. Cien días para la democracia, emitido el 15 de octubre de 1977. 
grandes temas que puedan rozar la unidad nacional, la independencia o la seguridad de la Patria, nada (...). Pero, en cambio, sí decimos que de actitud y predisposición al diálogo pacífico, todo, de abrir el juego político para normalizar la vida cotidiana, todo (...)"22.

\section{La Opinión pública ante las actuaciones terroristas}

Como ya se ha apuntado, el tratamiento que la cadena pública dio al terrorismo iba encaminado, a conformar una opinión pública que fuera contraria a reaccionar de manera inmovilista, rupturista o violenta ante los exaltados y que, a pesar de la inestabilidad político-social que generaba cada acción de ETA y la inseguridad que provocaba en relación a la consecución exitosa del proceso democratizador, no focalizara sus preocupaciones en el terrorismo y continuara teniendo fe en el proyecto de cambio político que se estaba desarrollando en España. En este sentido, las encuestas del CIS muestran un sentir general que guarda bastante relación con el discurso que se trasmitió desde la pequeña pantalla.

Así, en 1976, con motivo del secuestro por parte del GRAPO de Antonio María de Oriol y Urquijo, presidente del Consejo de Estado, se preguntó a los españoles cuál era la postura que consideraban que debería seguir el Gobierno ante los secuestros políticos. El $36 \%$ de los encuestados se mostró partidario de que se mantuviera firme sin caer en retroceso y el $21 \%$ apostaba no sólo por la firmeza sino también por la ampliación de las libertades ${ }^{23}$. Por otra parte, a los pocos días de la ofensiva terrorista, que aconteció durante la llamada Semana negra de finales de enero de 1977, se volvió a preguntar a los ciudadanos acerca de las posibles consecuencias que el terrorismo podría tener en la evolución democrática del país. Prácticamente la mitad de los encuestados -un 49\%-se manifestaba optimista ante el futuro de la Transición, considerando que la violencia dilataría sólo un poco o nada la consecución del proceso, frente al $26 \%$ que creía que lo retrasaría mucho o bastante. Este optimismo se desarrollaba en consonancia con la línea editorial de Televisión Española, de ahí, en gran medida, que el $61 \%$ de los encuestados calificara de acertada o muy acertada la actuación de los dirigentes políticos que apostaron por proseguir firmemente con la democratización del país ${ }^{24}$.

En relación con esa confianza en el proceso de cambio y ese clima de optimismo, que podría llegar incluso a confundirse con una actitud de cierta indiferencia hacia el terrorismo, llama la atención como, frente al aumento constante de la violencia y del número de víctimas, no se produjo el incremento lógico de la preocupación social acerca del terrorismo ni llegó

21 Ibidem.

22 Centro de Documentación de TVE, Discurso de Suárez con motivo de la llamada "Semana negra", emitido el 29 de enero de 1977.

23 Estudio no 1117 del CIS. Ámbito nacional. Universo: mayores de 21 años. Muestra: 1061 entrevistas. Fecha del trabajo de campo: 2627 de diciembre de 1976.

24 Estudio no 1117 del CIS. Ámbito nacional. Universo: mayores de 21 años. Muestra: 1389 entrevistados. Fecha del trabajo de campo: 57 de febrero de 1997. 
a disminuir la fe en que este problema desapareciera en un futuro. Así, a finales de 1979, tras un año donde las muertes por actos terroristas habían alcanzado cifras hasta entonces desconocidas, el barómetro de opinión pública del CIS reveló que tan sólo el $17 \%$ de los encuestados se mostraba más preocupado por la violencia terrorista que por los demás problemas que se les presentaba en la encuesta: crisis energética, desigualdades sociales, moralidad, paro, seguridad social, relaciones internacionales, precios, orden público y autonomías ${ }^{25}$.

La principal preocupación que tenían los españoles, según el 47\% de la muestra, era el paro; el cual superaba en 30 puntos al terrorismo, que ocupaba el segundo lugar en la escala. En relación con los problemas expuestos como variables, se preguntó a los entrevistados sobre cuál sería el futuro de cada uno de ellos. Con respecto al terrorismo, la respuesta mayoritaria -un 31\% - era la de que la situación mejoraría. Un optimismo en el futuro que sólo era superado por la confianza de los encuestados en las relaciones internacionales -45\%-y en el proceso autonómico -un 38\%-; porque, en relación con el resto de las preocupaciones planteadas, las respuestas más escogidas solieron ser, en líneas generales salvo en el caso de la seguridad social, más pesimista (empeorará o seguirá igual).

Así pues, la opinión pública se mostró optimista ante un terrorismo cada vez más virulento, apostó por la firmeza más que por la negociación y expresó su apoyo a la actuación de los dirigentes políticos, sintiéndose segura de que la violencia terrorista no sería un escollo insalvable para la consecución del cambio democrático. Por tanto, teniendo en cuenta la coincidencia entre el discurso explicativo de la realidad española frente al terrorismo que defendía la televisión y la sociedad, se podría afirmar que TVE, junto con otros instrumentos socializadores, pudo influir en la conformación de la opinión pública en España a través del tratamiento que dio al terrorismo etarra.

Posiblemente, en los contenidos sobre terrorismo, la cadena estatal no buscaba, de manera prioritaria, un efecto persuasivo directo que cambiara las actitudes de los televidentes a la manera de una acción inmediata de estímulo-respuesta. Bastaría con que la información con respecto a este ámbito de la actualidad estuviera controlada, para que cuando llegara al público receptor creara un pseudoentorno, a la manera de Lippmann (2003), que afectara a las actitudes, cumpliéndose así el objetivo buscado por el emisor. La televisión, como explica Gerbner, ocupa un lugar tan destacado en la vida cotidiana que ha adquirido la capacidad de dominar el "ambiente simbólico" de los espectadores. La versión televisiva del mundo, y en este caso la que ofrece este medio sobre la violencia etarra, modela la percepción del público y acaba logrando que este sustituya lo que le aporta su experiencia personal o lo que ha obtenido a través de las otras posibles vías de conocimiento, por lo que le ofrece la pequeña pantalla (Gerbner, 1973).

${ }^{25}$ REIS, “Barómetro de opinión pública. Noviembre 1979”, nº 9, enero-marzo, 1980, pp. 221-237. 


\section{Conclusiones}

Como se ha querido exponer a lo largo de estas páginas, Televisión Española desarrolló una política mediática estudiada a la hora de enfrentarse al fenómeno terrorista en un momento tan delicado como fue la Transición. El poco espacio con el que el terrorismo contó en la agenda televisiva refleja una intención clara de alterar ese "ritual" del que nos habla Piñuel (1986). Teniendo en cuenta los estudios del CIS y el resultado final de la Transición se podría considerar que el punto de vista a través del cual se trataron los actos de violencia y los mensajes que se transmitieron en la cadena estatal ante los atentados perpetrados por ETA fueron indispensables para conformar una opinión pública que reaccionara de manera democrática y disciplinada ante la creciente escalada terrorista.

Esa estrategia mitigó la provocación de los efectos sociales que los exaltados perseguían. En vez de producirse una respuesta autoritaria o un enfrentamiento generalizado se favoreció que la opinión pública, modelada en gran medida por lo emitido en la televisión estatal, rechazara la violencia, se mostrara partidaria de proseguir por la vía de la reforma política y comprendiera, como ha expuesto Reig Cruañes (2000), que la desestabilización nacional y la involución entrañaban el auténtico peligro. La moderación de la opinión pública reflejó una desconfianza creciente en los radicalismos y en los "salvadores nostálgicos" (Reig Cruañes, 2000: 750) y, cómo ocurrió, en general, ante lo relacionado con la evolución democrática, se produjo una "reunificación de la opinión pública sobre fundamentos democráticos y reformistas" (Reig Cruañes, 2000: 750).

La violencia terrorista avivó el sentimiento de temor y como consecuencia fortaleció los anhelos de una alternativa pacífica que posibilitara instaurar una democracia estable en España. La tendencia moderadora y el miedo ejercieron el papel de "nodrizas de la libertad", si empleamos la expresión acuñada por López Pintor; puesto que gracias a su generalización en la opinión pública, en gran medida a través del medio televisivo, los dirigentes del cambio consiguieron el apoyo necesario para llevar a cabo el proceso democratizador (López-Pintor, 1982: 59).

De todo lo expuesto acerca del tratamiento que TVE dio a las acciones de ETA, podría deducirse el modo a través del cual se consiguió que el cambio democrático fuera vivido, y posteriormente recordado, como un proceso pacífico a pesar de que la constante presencia de la violencia terrorista pusiera en peligro la consecución de lo planificado. La televisión se había convertido en pocos años en uno de los medios más consumidos por la sociedad española y, por lo tanto, todo aquello que se transmitía por la pequeña pantalla marcaba, en gran medida, las pautas de pensamiento de la sociedad ante determinados temas. De ahí que la televisión estatal pareciera ser consciente de que debía estudiar con celo cómo tratar las cuestiones relacionadas con el terrorismo etarra y planificar con detalle no sólo los contenidos que se difundían sino la forma en la que eran transmitidos, tanto desde el punto de vista del lenguaje empleado como el de las imágenes, los sonidos o la estructura de los guiones. 
Hay que tener en cuenta que este medio, como defiende Martín Serrano, "interviene en la valoración de la realidad tanto por sus juicios de valor explícitos, como por la valoración implícita que lleva a cabo sobre los temas que aparecen en la pequeña pantalla" (Martín Serrano, 1981: 43); lo cual se acrecienta cuando se trata de cuestiones tan delicadas y trascendentales como es el terrorismo en una etapa histórica de transición. Por lo tanto, la televisión, como agente mediador que es, afectó a la interpretación que pudo asumir gran parte de la audiencia sobre la realidad de la violencia de los exaltados.

En cuanto a la aprobación o desaprobación del terrorismo, la cadena estatal habitualmente no hizo uso de categorías de juicios éticos maniqueos del tipo bueno o malo; lo cual no significa que en su programación no existiera ninguna clase de posicionamiento moral sino que los criterios de asentimiento o condena eran introducidos en el relato con sutileza y de manera no explícita. Este tipo de difusión implícita y el añadido que presenta la televisión frente a otros medios en cuanto que es capaz de ocultar al espectador el mediador del mensaje, favorece que el público no aprecie "que en las imágenes del televisor, se le propone además una visión del mundo y una interpretación de la realidad. (...) La televisión reproduce todo, excepto su manera de reproducir en tanto que mediador" (Martín Serrano, 1981: 51-52).

Consciente de su influencia, Televisión Española trató de emitir un mensaje de serenidad y confianza en la instauración de la democracia. En los reportajes de Informe Semanal, durante los cuales se hacía alusión a las acciones de ETA, eran una constante las referencias al consenso, el pluralismo, la reconciliación y la tolerancia como bases de la convivencia y el entendimiento; junto al rechazo, por contraposición, a las posturas extremistas, intransigentes o violentas. Los españoles debían permanecer unidos, evitando cualquier tipo de exaltación, para así poder centrarse en la meta que debía alcanzarse: la creación de un estado democrático.

Por lo tanto, la pequeña pantalla actuó durante la Transición como un medio socializador cuya influencia según sus dirigentes podía servir para construir identidades y, como consecuencia, garantizar con sus emisiones la unidad social de España y, así, colaborar en la materialización del cambio político en el país (Martín Jiménez, 2011). Este planteamiento constituyó los cimientos sobre los cuales se confeccionó el tipo de tratamiento que iba a darse en televisión al terrorismo. Las tácticas discursivas y representativas de este medio estarían condicionadas por la necesidad de forjar, utilizando la noción de David Morley, "la familia nacional" (Morley, 2000). La estrategia ante la violencia terrorista se encaminaría, frente al tratamiento como "historia en directo" que se empleó en otras ocasiones (Dayan y Katz, 1995) a divulgar principios de integración comunitaria. Para encarar al terror organizado, la nación, una vez mediatizada, debía ser entendida por la audiencia como un "hogar simbólico". La esfera privada se socializaría a través de las referencias televisivas; las cuales transformarían al colectivo social en un conjunto homogéneo, un frente unido, una familia dispuesta a resistir a cualquier tipo de impedimento democratizador ${ }^{26}$.

26 Una vez consolidada la democracia en España, se observa un cambio en la manera con que los medios televisivos han tendido a tra- 
El terrorismo, según lo que transmitió la cadena estatal, tenía como único objetivo llevar a cabo maniobras desestabilizadoras que provocaran tensión y atacaran directamente los pilares de la naciente democracia. Sin embargo, esta condena mediática a los actos terroristas no vino acompañada de una difusión muy amplia. Los numerosos atentados cometidos, por ejemplo, contra policías o guardias civiles casi no tuvieron resonancia en dicho medio fuera del ámbito estrictamente informativo de los Telediarios. Hubo que esperar a que las víctimas fueran destacados políticos, empresarios o personas con cargos de gran responsabilidad para que se hiciera un hueco en la parrilla televisiva donde cupiera la información sobre las consecuencias de la violencia etarra.

A pesar de la relevancia del terrorismo y su repercusión directa en el discurrir del cambio político, Televisión Española no llegó a tratar este problema con profundidad ni con perspectiva; más bien al contrario, se optó, cuando no por el silencio, por el sensacionalismo, la crónica negra o el tono trivial. Esto pudo provocar que lo relacionado con ETA llegara al espectador con una cierta frivolidad que podía causar, quizá de manera intencionada, que se relativizara lo sucedido. En escasas ocasiones los atentados fueron tratados con detenimiento por TVE y cuando se hizo no se ofreció un producto periodístico capaz de mostrar al espectador en profundidad las secuelas de este dramático problema y la implicación social y política que era necesaria para afrontarlo.

En la búsqueda del cumplimiento del objetivo de implantar con éxito una democracia en España pese a la amenaza etarra, TVE tendió a incluir en sus guiones, como hemos visto en los reportajes analizados, argumentos cargados de valor positivo. La Transición era una etapa muy delicada en la que había mucho en juego y en la cual el terrorismo constituía una lacra capaz de producir la regresión del proceso; ante ello, las emisiones de la cadena estatal centraron sus contenidos en transmitir la imagen de un Gobierno fuerte, capaz de actuar con firmeza y garantizar la seguridad de la ciudadanía. La dirección de la cadena estatal se esforzó por no difundir sentimientos de desánimo, desestabilización o incertidumbre; así, cuando se informaba sobre un atentado, o bien se contaba de forma somera para acto seguido enlazarlo con una noticia positiva, o se mostraba como algo sucedido mucho tiempo atrás y, por lo tanto, como un escollo ya superado.

No sólo era importante qué información se difundía sobre las actuaciones terroristas sino de qué manera era difundida. Se trataba de consolidar el nuevo discurso hegemónico, el democrático frente al autoritario del franquismo, y en esa labor el lenguaje empleado iba a jugar un papel crucial. Mediante la elección de unas u otras palabras se podría construir una determinada identidad de la violencia, cobrando esta un sentido diferente según los términos utilizados. Por eso, los asesinatos cometidos se solían denominar "actos" o se tendió a aludir a los disturbios y a la violencia callejera, por muy graves que fueran, como "actitudes violentas” sin más. La Televisión estatal recurrió también a expresiones eufemísticas para

tar el problema del terrorismo, tanto a nivel nacional como internacional. La "historia en directo" se ha convertido en una de las estrategias dominantes a la hora de difundir información relativa a las bandas terroristas y sus acciones (Rueda, Coronado y Sánchez García, 2009). 
hacer referencia al terrorismo sin nombrarlo de manera específica. Por ejemplo, a la hora de nombrar a ETA y a sus atentados se hablaba de "problemática vasca", con lo cual se provocaba un giro en el significado de la banda y en las repercusiones de sus actos, porque era tratada como si sus actuaciones afectaran únicamente al País Vasco y no a toda España.

Así, durante los primeros años de la Transición en la programación de Televisión Española no se intentó, utilizando la terminología empleada por Keane, "democratizar la violencia” (Keane, 2004). Como expone este autor, la única vía para poder enfrentarse al terrorismo y que este no se convierta en un peligro mortal para el sistema es la de su democratización. TVE, debido a su carácter estatal y el gran vínculo que tenía con el Gobierno, quizá estaba más preocupada por culminar el proceso de transición que por terminar con la lacra del terrorismo; para lo cual, según las diez reglas de Keane, hubiera sido necesario que la cadena pública hubiera hecho uso de todas las vías posibles de comunicación que ofrece la televisión para informar sobre los actos de violencia, de tal manera que se convirtieran en objeto de debate público tanto sus causas, como sus efectos o las posibles soluciones que podrían ejecutarse para poner fin a dicha violencia (Keane, 2004: 191).

A modo de síntesis de lo que fue el tratamiento que TVE hizo del terrorismo etarra, resulta expresiva una cita sacada del guión de un programa especial que España hoy dedicó, en 1977, a la figura de Adolfo Suárez y a los acontecimientos más relevantes acaecidos desde su llegada al poder, en el que, tras hacer un recuento laudatorio se dejaba bien claro que, por encima de todos los escollos y problemas aún sin superar, y que no se habían tratado en el relato, lo más importante es que se había cumplido el objetivo democratizador: "Pero no se crean que se recoge en este recuento todo lo ocurrido en España. En medio de esta narración quedan acciones y tensiones que no tendrían cabida en este reportaje. La resistencia de grupos extremistas que fue necesario controlar, la resistencia de los sectores más conservadores que no deseaban ningún tipo de cambio...; el balance final, de todas formas, es el mismo: se hizo la democracia”27.

\section{Bibliografía}

Casals Meseguer, X. (2009): “¿Existió una estrategia de la tensión en España?”, Historia del Presente, vol. 14, pp. 25-38.

Clutterbuck, R. (1985): Los medios de comunicación y la violencia política. Pamplona: Universidad de Navarra.

Dayan, D. y Katz, E. (1995): La historia en directo. La retransmisión televisiva de los acontecimientos. Barcelona: Gustavo Gili. Domínguez Iribarren, F. (2000): “La violencia nacionalista de ETA”, en Juliá, S. (dir.): Violencia política en la España del siglo $X X$. Madrid: Taurus.

Elorza, A. (coord.) (2000): Historia de ETA., Madrid: Temas de Hoy.

27 Centro de Documentación PP II TVE, España hoy. Especial Adolfo Suárez, emitido en 1977. 
Gerbner, G. (1973): “Cultural Indicators - the Third Voice”, en Gerbner, G., Gross, L. y Melody, W. (comps.): Communications Technology and Social Policy. Nueva York: Wiley, pp. 553-573.

Jenkins, B. M. (1984): “Responsabilidad de los medios informativos", en VVAA.: Terrorismo y medios de comunicación social. Ministerio del Interior. Madrid: Secretaría General Técnica, pp. 51-58.

Keane, J. (2004): Violence and democracy. United Kingdom: Cambridge.

López-Pintor, R. (1982): La opinión pública española del franquismo a la democracia. Madrid: CIS.

Magro, B. (ed.) (2003): Informe Semanal. 30 años de historia. Barcelona: Plaza y Janés.

Martín Jiménez, V. (2011): Televisión Española y la Transición democrática: Comunicación política y promoción del cambio social durante la etapa del consenso (1976-1979), Tesis doctoral, Valladolid, Universidad de Valladolid.

Martín Serrano, M. (1981): “La influencia social de la televisión: niveles de influencia (I)”, Revista Española de Investigaciones Sociológicas, vol. 16, pp. 39-55.

Morley, D. (2000): Home territories. Media, Mobility and Identity. Londres: Nueva York: Rotledge.

Muñoz Alonso, A. (1986): “Golpismo y terrorismo en la transición democrática española”, Revista Española de Investigaciones Sociológicas, vol. 36, pp. 25-33.

Nacos, B. (2002): Mass Mediated terrorism. The central role of the media in terrorism and counterterrorism. Oxford: Rowman and Littlefield Publishers INC.

Papacharissi, Z. y Oliveira, M. de F. (2008): "News frames terrorism: A comparative análisis of frames employed in terrorism converage in US and UK newspaper”, The International journal of press/politics, vol. 13, pp. 52-74.

Pearlstein, R. M. (1991): “Tuned- in Narcissus: the Gleam in the Camera's Eye”, en Alexander, Y. and Picard, R. G. (ed.): In he Camera's Eye, New Coverage of terrorist events, pp. 49-57.

Picard, R. (1993): Media Portrayals of terrorism: Functions and meaning of news coverage. Ames: Iowa State University Press.

Piñuel, J. L. (1986): El terrorismo en la Transición española (1972-1982). Madrid: Fundamentos.

Pulgar Gutiérrez, Ma B. (2004): Víctimas del Terrorismo, 1968-2004. Madrid: Dykinson.

Reig Cruañes, J. (2000): Opinión pública y comunicación política en la transición democrática. Alicante: Universidad de Alicante.

Reinares, F. (1993): “Democratización y terrorismo en el caso español”, en Tezanos, J. F., Cotarelo, R., De Blas, A. (eds.): La transición democrática española. Madrid: Sistema, pp. 611-644.

Rodrigo, M. (1991): Los medios de comunicación ante el terrorismo. Barcelona: Icaria. 
Rueda, J. C., Coronado Ruiz, C. y Sánchez García, R. (2009): “De ETA a Al-Qaeda. Cultura política y representación televisiva del terror", De la Sociedad Industrial a la Sociedad de la Comunicación, X Congreso de la Asociación de Historiadores de la Comunicación, Bilbao.

Sánchez Cuenca, I. (2009): “La violencia terrorista en la transición española a la democracia”, Historia del Presente, vol. 14, pp. 9-24.

Sánchez- Duarte, J. M. (2009): “Narrativas y portavoces del terrorismo mediatizado”, Revista Latina de Comunicación Social, vol. 64, pp.481-490.

Sánchez-Duarte, J. M y Sampedro Blanco, V. F. (2011): "Visibilidad mediática y terrorismo: El caso de las víctimas de ETA", Textual \& Visual Media, vol. 4, pp. 183-210.

Torres Romay, E. (2006): “El tratamiento de la imagen en los atentados del 11-M. Terrorismo y violencia en prensa”, Revista Latina de Comunicación Social, vol. 61.

Tusell, J. (1999): La transición española a la democracia. Madrid: Historia 16.

Wilkinson, P. (1990): “Terrorism and propaganda”, en Alexander, Y. and Latters ed.: Terrorism and The Media/ Dilemmas for Government, Journalists and The Public. United States: Brassey’s Terrorism Library, pp. 26-33. 